\title{
Stochastic Modeling and Simulation of the Formation of Carbon Molecular Sieves by Carbon Deposition
}

\author{
L. T. Fan ${ }^{*}$, Andres Argoti, Walter Walawender, and Song-Tien Chou ${ }^{\dagger}$ \\ Department of Chemical Engineering, Kansas State University, Manhattan, Kansas 66502, \\ U. S. A.
}

\footnotetext{
${ }^{*}$ To whom correspondence should be addressed. Tel.: (785) 532-5584. Fax: (785) 532-7372. E-mail: fan@cheme.ksu.edu.

${ }^{\dagger}$ Permanent address: Department of Finance and Banking, Kun Shan University of Technology, Yung-Kang City, Tainan Hsien, 71003 Taiwan.
} 


\section{Appendix A. Detailed Derivation of the Master Equation}

As mentioned in the text, the master, i.e., governing, equation can be derived as the gainloss equation resulting from probability balance (Oppenheim et al., 1977; van Kampen, 1992). The derivation of the master equation for the pure-birth process of concern, which is porenarrowing, is elaborated below.

With $\mathrm{N}(\mathrm{t})=\mathrm{n}$ given, it is assumed that during time interval $(\mathrm{t}, \mathrm{t}+\Delta \mathrm{t})$ : (1) the conditional probability that a birth event will occur, i.e., a packet will deposit onto an open pore, is $\alpha\left(n_{M}-n\right) \Delta t+o(\Delta t)$; and (2) the conditional probability that more than one event will occur is $\mathrm{o}(\Delta \mathrm{t})$, which is defined such that

$$
\lim _{\Delta t \rightarrow 0} \frac{\mathrm{o}(\Delta \mathrm{t})}{\Delta \mathrm{t}}=0
$$

Naturally, the conditional probability of no change in the number of depositing packets during this time interval is $\left[1-\alpha\left(n_{M}-n\right) \Delta t-o(\Delta t)\right]$.

Let the probability that exactly $\mathrm{n}$ packets have already deposited at time $\mathrm{t}$ be denoted as $\mathrm{p}_{\mathrm{n}}(\mathrm{t})=\operatorname{Pr}[\mathrm{N}(\mathrm{t})=\mathrm{n}], \mathrm{n}=0,1,2, \ldots, \mathrm{n}_{\mathrm{M}}-1, \mathrm{n}_{\mathrm{M}}$. Then, for the two adjacent time intervals, $(0, \mathrm{t})$ and $(t, t+\Delta t)$, the occurrence of exactly $n$ packets depositing at time $(t+\Delta t)$ can be realized in the following mutually exclusive ways (Figure A.1).

(1) With a probability of $\mathrm{p}_{\mathrm{n}-1}(\mathrm{t})\left\{\alpha\left[\mathrm{n}_{\mathrm{M}}-(\mathrm{n}-1)\right] \Delta \mathrm{t}+\mathrm{o}(\Delta \mathrm{t})\right\}$, exactly one packet will deposit during the time interval $(\mathrm{t}, \mathrm{t}+\Delta \mathrm{t})$, provided that exactly $(\mathrm{n}-1)$ packets have already deposited at time $t$. 
state and

state probability

at time $t$ probability of ocurrence

state and

state

probability

at time $(\mathrm{t}+\Delta \mathrm{t})$

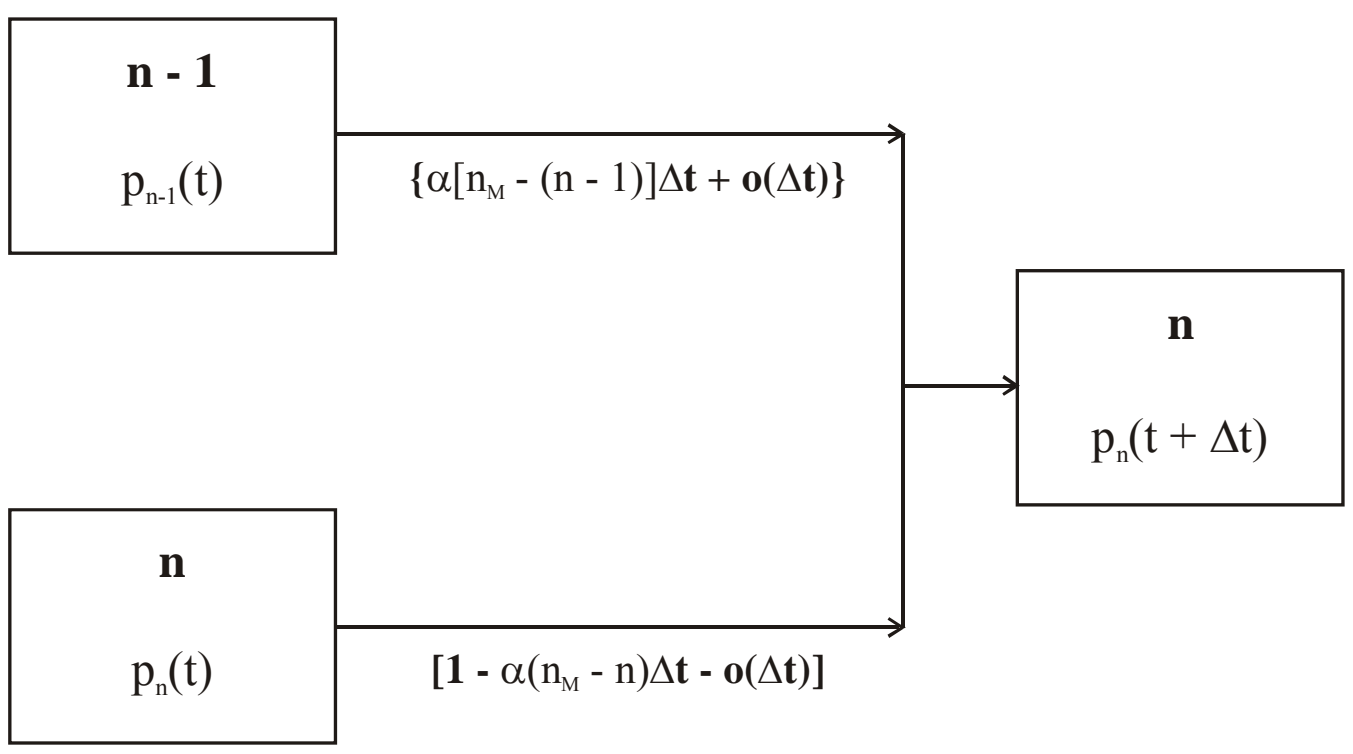

Figure A.1. Probability balance involving the mutually exclusive events in the time interval, $(\mathrm{t}, \mathrm{t}+\Delta \mathrm{t})$. 
(2) With a probability of $o(\Delta t)$, exactly j packets will deposit during the time interval $(t, t+\Delta t)$, provided that exactly $(n-j)$ packets have already deposited at time $t$, where $2 \leq \mathrm{j} \leq \mathrm{n}_{\mathrm{M}}$

(3) With a probability of $p_{n}(t)\left[1-\alpha\left(n_{M}-n\right) \Delta t-o(\Delta t)\right]$, no additional packet will deposit during the time interval $(\mathrm{t}, \mathrm{t}+\Delta \mathrm{t})$, provided that all $\mathrm{n}$ packets have already deposited at time $\mathrm{t}$.

Summing all these probabilities and consolidating all quantities of o( $\Delta \mathrm{t})$ yield (Figure A.1)

$$
\mathrm{p}_{\mathrm{n}}(\mathrm{t}+\Delta \mathrm{t})=\mathrm{p}_{\mathrm{n}}(\mathrm{t})\left[1-\alpha\left(\mathrm{n}_{\mathrm{M}}-\mathrm{n}\right) \Delta \mathrm{t}\right]+\mathrm{p}_{\mathrm{n}-1}(\mathrm{t})\left\{\alpha\left[\mathrm{n}_{\mathrm{M}}-(\mathrm{n}-1)\right] \Delta \mathrm{t}\right\}+\mathrm{o}(\Delta \mathrm{t})
$$

Rearranging this equation and taking the limit as $\Delta t \rightarrow 0$ yield the master equation of porenarrowing as given below.

$$
\begin{gathered}
\frac{d}{d t} p_{n}(t)=\alpha\left[n_{M}-(n-1)\right] p_{n-1}(t)-\alpha\left(n_{M}-n\right) p_{n}(t), \\
n=1,2, \ldots, n_{M}-1, n_{M}
\end{gathered}
$$

This is Eq. 2 in the text. For $n=0$, the term, $\alpha\left[n_{M}-(n-1)\right] p_{n-1}(t)$, in the above expression is absent; thus,

$$
\frac{\mathrm{d}}{\mathrm{dt}} \mathrm{p}_{0}(\mathrm{t})=-\alpha \mathrm{n}_{\mathrm{M}} \mathrm{p}_{0}(\mathrm{t})
$$

This is Eq. 3 in the text. 